Rosi Braidotti, a Reader of Spinoza:

Affirmative Politics beyond Humanism

\title{
Rosi Braidotti, lectora de Spinoza: una politica afirmativa más allá del bumanismo
}

\author{
Juan Dorado Romero
}

Escuela de Humanidades y Educación del Tecnológico de Monterrey (Campus de Ciudad de Mexico) jdoradoromero@gmail.com

DOI: https://doi.org/10.15366/bp2021.27.003

Bajo Palabra. II Época. № 27. Pgs: 63-80

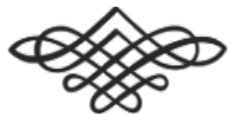


Recibido: 30/01/2020

Aprobado: 07/05/2021

\section{Resumen}

En este artículo propongo un acercamiento a la obra de la filósofa italiana Rosi Braidotti para rastrear su particular lectura y recuperación del legado ético y político de Baruch Spinoza. La ontología monista de Spinoza ha servido a nuestra autora para plantear una forma novedosa y radical de posthumanismo crítico, que le ha servido tanto para evidenciar las límites teóricos y conceptuales del humanismo tradicional como para avanzar en una línea de investigación que comienza por la aceptación del continuum naturaleza-cultura. Revisamos la propuesta de Braidotti de una ética y una política afirmativa que sirvan para abordar la complejidad de nuestros tiempos presentes.

\section{Abstract}

In this article, I propose an approach to Italian philosopher Rosi Braidotti's work to trace her singular reading and recovery of the ethical and political legacy of Baruch Spinoza. Spinoza’s monistic ontology has enabled her to propose a novel and radical form of critical post-humanism, which helps both to demonstrate the theoretical and conceptual limits of traditional humanism and to advance in a line of research that begins with the acceptance of the Nature-Culture continuum. I review Braidotti's proposal for affirmative ethics and politics that address the complexity of our present times.
Palabras clave: Braidotti, Spinoza, continnum naturaleza-cultura, politica afirmativa, vulnerabilidad, posthumanismo.
Keywords: Braidotti, Spinoza, Nature-Culture Continuum, Affirmative Politics, Vulnerability, Posthumanism. 
Sólo una triste y torva superstición puede prohibir el deleite. ¿Por qué saciar el hambre y la sed va a ser más decente que desechar la melancolía? Tal es mi regla, y así está dispuesto mi ánimo ${ }^{1}$.

SPINOZA

\section{Introducción: ¿ Spinoza feminista?}

ANTES DE CUALQUIER OTRA CONSIDERACIÓN, lancemos una pregunta porque se trata de una cuestión que está lejos de ser obvia: ¿por qué una de las pensadoras feministas más leídas y discutidas del panorama académico contemporáneo repite una y otra vez que Spinoza es su "filósofo preferido" 2? ¿Qué encuentra Rosi Braidotti, autora de referencia de la teoría feminista contemporánea, en un pensador del siglo XVII, es decir, de una época en la que las mujeres ni siquiera eran consideradas ciudadanas? Un pensador en el que, además, escasean sus referencias a esa mitad de la especie humana tradicionalmente domesticada, en el sentido de que fueron recluidas en las labores del hogar, dentro de los límites del espacio privado y, por tanto, excluidas de un espacio público destinado a los hombres y, concretamente en su época, a los hombres cristianos propietarios. Un espacio del que el mismo Baruch Spinoza (1632-1677), por su condición de judío sefardita, no podía formar parte en unos Países Bajos que padecían un conflicto cruento entre las diferentes ramas del cristianismo.

Aunque, como decimos, Spinoza escribió poco sobre la condición femenina, más le valdría haberse quedado callado si lo leemos desde nuestro presente. Su inacabado Tratado politico concluye diciendo que varones y mujeres no son iguales "por naturaleza", ya que la experiencia demostraba que, en ninguna de las naciones conocidas, se podía encontrar un gobierno en que los dos sexos gobernaran por igual $^{3}$. Esto, desde luego, sorprende en un filósofo que siempre nos empuja a reflexionar sobre lo que se oculta bajo las apariencias y las normas sociales. Su pensamiento resultó ser tan subversivo para la teología y la moral de su tiempo que acabó por ser separado de la comunidad judía de Ámsterdam y que, tras la publicación de su Tratado teológico-político, fue detestado y perseguido también por católicos y

\footnotetext{
1 Spinoza, B., Ética, trad. de V. Peńa, Madrid, Alianza, 2011, IV, prop. 45, esc., p. 365.

2 Braidotti, R., Lo posthumano, trad. de J. C. Gentile, Barcelona, Gedisa, 2015, p. 71.

3 Spinoza, B., Tratado político, trad. de A. Domínguez, Madrid, Alianza, 1986, cap. XI, \$4, p. 223.
} 
protestantes a los que, a pesar de su mutua inquina, unió su odio hacia este hombre discreto que se atrevió a hacer una hermenéutica crítica y situada de las Sagradas Escrituras. Como escribió Gilles Deleuze (1925-1995), uno de los maestros de las feministas spinozistas, "si bien no es infrecuente que un filósofo acabe procesado, es más raro que comience por una excomunión y un intento de asesinato" ${ }^{4}$. No está de más recordar la virulencia del herem que la sinagoga sefardita de Ámsterdam lanzó contra él en 1656:

Excomulgamos, maldecimos y separamos a Baruch Espinosa, con el consentimiento de Dios bendito y con el de toda su comunidad [...] que sea maldito de día y maldito de noche; maldito cuando se acueste y maldito cuando se levante; maldito cuando salga y maldito cuando entre; que Dios no lo perdone; que su cólera y su furor se inflamen contra este hombre y traigan sobre él todas las maldiciones escritas en el libro de la Ley; que Dios borre su nombre del cielo y lo separe de todas las tribus de Israel ${ }^{5}$.

Curiosamente, esta condena recuerda las imprecaciones que algunos grupos religiosos y conservadores de nuestros días lanzan contra las pensadoras y activistas feministas por cuestionar los roles tradicionales en la familia y en la sociedad, que siguen situando a las mujeres y a los disidentes sexuales en posiciones de inferioridad y discriminación estructural.

Antes de proseguir conviene, no obstante, detenernos brevemente en los argumentos esgrimidos por Spinoza para seguir negando la ciudadanía a las mujeres en un Estado democrático. Junto a ellas, el filósofo apartó del espacio público tanto a los siervos como a los niños, es decir, a todos aquellos que carecen de autonomía porque su existencia material depende de otros y no son libres para determinar su propia vida ${ }^{6}$. Este argumento sitúa a Spinoza en la tradición política republicana, según la cual no es concebible la libertad política, esto es, la participación activa en las decisiones públicas, si no se tiene asegurado el sustento económico. La persona dependiente, atenazada por el miedo a no poder sobrevivir por sus propios medios, no podría formar criterios libres pues no puede perder el favor de quien la tiene bajo su potestad ${ }^{7}$. Por lo tanto, su juicio tenderá a ser el mismo de quien los provee

\footnotetext{
${ }^{4}$ Deleuze, G., Spinoza: filosofia práctica, trad. de A. Escohotado, Buenos Aires, Tusquets, 2004, p. 14.

5 Citado en Peña, V., "Introducción”, en Spinoza, B., Ética, op. cit, p. 15.

${ }^{6}$ Ver Sharp, H., "Eve's Perfection: Spinoza on Sexual (In)Equality", en Journal of the History of Philosophy, vol. 50, $\mathrm{n}^{\circ} 4$ (2012), pp. 564-565. https://doi.org/10.1353/hph.2012.0068

7 "Tiene a otro bajo su potestad, quien lo tiene preso o quien le quitó las armas y los medios de defenderse o de escaparse, o quien le infundió miedo o lo vinculó a él mediante favores, de tal suerte que prefiere complacerle a él más que a sí mismo y vivir según su criterio más que según el suyo propio. Quien tiene a otro bajo su potestad de la primera o la segunda forma, sólo posee su cuerpo, pero no su alma; en cambio, quien lo tiene de la tercera o la cuarta forma, ha hecho suyos tanto su alma como su cuerpo, aunque sólo mientras persista el miedo o la esperanza”. Spinoza, B., Tratado político, op. cit., cap. II, $\$ 10$, p. 90.
} 
de los medios de subsistencia. Actualmente algunos autores defienden la introducción de una renta básica universal e incondicional para fortalecer nuestros regímenes democráticos siguiendo estos argumentos clásicos de la tradición republicana ${ }^{8}$. Por otro lado, esa desigualdad "por naturaleza" con la que Spinoza mantiene la exclusión política de las mujeres no debería considerarse de forma aislada respecto a su particular concepción naturalista. De este modo, siguiendo su ontología monista, no habría que entender la naturaleza como separada de la cultura por la misma razón por la que el cuerpo no está separado del alma, siendo dos atributos de la misma y única sustancia. $\mathrm{O}$ en sus propias palabras: "el alma y el cuerpo son una sola y misma cosa, que se concibe, ya bajo el atributo del Pensamiento, ya bajo el atributo de la Extensión"'. Más aún, el mismo Spinoza anteriormente había afirmado en el Tratado Teológico-Politico que no es la naturaleza, sino las leyes y las costumbres, lo que distingue a las diferentes naciones ${ }^{10}$, y puesto que esas diferencias son producto del artificio humano, podrían ser igualmente modificadas en un futuro. Poco antes de decantarse por la exclusión "natural" de las mujeres, Spinoza explica en su inacabado Tratado Político que, si la subordinación femenina se ha basado en la ley y no en causas naturales, no hay ninguna razón para prescindir de las mujeres en una democracia. De ahí que, desde una perspectiva feminista - a partir de la comprensión de los orígenes históricos y contingentes del patriarcado-, podamos establecer una discusión de Spinoza contra sí mismo para desacreditar esa página negra de su legado.

Regresando a la cuestión inicial, ¿por qué la filosofía de Spinoza se ha convertido en un puntal de los nuevos feminismos? Autoras como Moira Gatens o Hasana Sharp apuntan que, a pesar de su radical iconoclastia, Spinoza no era invulnerable a los prejuicios sexistas que predominaban en su día, lo que no impide que se puedan aprovechar y ampliar las ideas de este autor que sirvan y potencien los propósitos de la teoría feminista ${ }^{11}$. Y entre estas ideas, Hasana Sharp destaca fundamentalmente dos: su anti-individualismo y su anti-dualismo. ${ }^{12}$ La lectura que Rosi Braidotti hace del corpus spinoziano añade otra dimensión de su pensamiento: la de ser capaz de elaborar una ética antimoralista a partir de una cartografía de las pasiones humanas.

\footnotetext{
${ }^{8}$ Ver, por ejemplo, Raventós, D., y Casassas, D., "La renta básica y el poder de negociación de 'los que viven con permiso de otros", en Revista Internacional de Sociologia (RIS), n 34 (2003), pp. 187-201. https://doi. org/10.3989/ris.2003.i34.291. También de Casassas, D., Libertad incondicional: la renta básica en la revolución democrática, Barcelona, Paidós, 2018.

9 Spinoza, B., Ética, op. cit, III, prop. 2, esc., p. 213.

${ }^{10}$ Spinoza, B., Tratado teológico-político, trad. de A. Domínguez, Barcelona, Altaya, 1997, cap. XVII, p. 375.

11 Ver Balza, I., "Los feminismos de Spinoza: corporalidad y renaturalización", en Daimon. Revista Internacional de Filosofía, $\mathrm{n}^{\circ} 63$ (2014), p. 17. https://doi.org/10.6018/daimon/199491

12 Sharp, H., “¿Por qué Spinoza y el feminismo?”, Reflexiones marginales, n 51 (2019), consultado en https://2018. reflexionesmarginales.com/por-que-spinoza-y-el-feminismo/ (21/01/2020).
} 
En cuanto a la estructura de este artículo, en el primer apartado me centraré en la crítica de nuestra autora a la tradición humanista, mientras que en el segundo apartado analizaré sus propuestas para una ética y una política afirmativas, para concluir con su intención de construir "horizontes sociales de esperanza", un afecto ambiguo en la obra de Spinoza. Desde este momento, les invito a leer a esta lectora, les animo a seguir a Braidotti mientras lee gozosamente al filósofo maldito que renunció a la Academia para que ningún poder dominante coartara ni amedrentara su pensamiento.

\section{Violencia humanista}

NaCida en ItAlia, hija de EMigrantes crecida en Australia, formada intelectualmente en el París de la explosión postestructuralista y profesora desde la década de 1980 en los Países Bajos — la tierra donde nació y murió Spinoza—, Rosi Braidotti, la pensadora de los devenires nómadas, lleva décadas explorando y desplazando el estatuto epistemológico de lo humano más allá o más acá de lo establecido. Su obra gira en torno a preguntas que no deben darse por descontado: ¿qué es lo humano? ¿qué pertenece a esta categoría y qué queda fuera de ella? ¿cuáles son sus fronteras? ¿quiénes están legitimados a trazar esas fronteras? ¿en qué reside esa legitimidad? Lo humano ha funcionada históricamente como un mecanismo de inclusión y exclusión. Desde una perspectiva situada, como mujer sexuada y generizada, privilegiada en cuanto académica de una universidad europea, Braidotti es rotunda al afirmar que no puede sostenerse, con seguridad, que todos quienes están leyendo este artículo han sido siempre humanos. Mucho menos si nos remontamos al pasado; mucho menos si tomamos en cuenta que la historia de la modernidad occidental está indisociablemente unida desde hace siglos a procesos de colonización, despojo, expolio, humillación del diferente y deshumanización de poblaciones por razones sexuales, económicas o étnicas. La diferencia ha sido traducida como desigualdad de acceso a bienes básicos, como imposibilidad de ciudadanía, como inferiorización constante sancionada por las violencias directas, estructurales y culturales que seguimos presenciando y padeciendo de forma cotidiana.

Los dispositivos de exclusión van variando dependiendo del tiempo y el lugar donde nos situemos. Si como sostiene la antropóloga Rita Segato, "la primera colonia en la historia de la humanidad fue el cuerpo de la mujer" ${ }^{13}$, el racismo ha sido, según Foucault, la vía privilegiada del poder soberano para dotarse de legitimidad

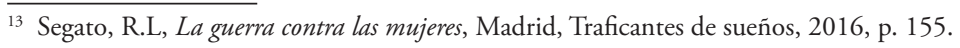


para matar y ha funcionado como el discurso biopolítico por excelencia ${ }^{14}$. Deberíamos ser muy conscientes de esto, concretamente en los países o territorios fronterizos con las regiones subalternas de la geopolítica del capital. No parece haber consenso sobre la humanidad de incontables seres con rasgos antropomórficos, si atendemos a las políticas migratorias del Norte global, centradas en la expulsión de lo distinto, en la devolución a sus lugares de origen o en su reclusión en campos de concentración. Se trata de prácticas de selección y supresión biológica en territorios cuyos gobiernos se adhieren a la Declaración Universal de los Derechos Humanos. De manera más atenuada, pero no menos cruel, escuchamos desde hace ya décadas la retórica de los "recursos humanos" y nos sometemos, de forma más o menos voluntaria, a las prácticas de inversión en "capital humano", una forma de tratar la vida en sí como fuente de una plusvalía tendencialmente infinita, que pone a trabajar al unísono cuerpo y mente para ser consumidos por un mercado insaciable ${ }^{15}$. El capitalismo parece haber aprendido, mucho antes que las principales tradiciones del humanismo occidental, que la separación cuerpo/mente es una trampa que la conciencia se hace a sí misma.

Como seńala Braidotti, necesitamos una teoría crítica materialista para "ser dignos de lo que nos ocurre" ${ }^{16}$. El capitalismo de nuestros días funciona, como estudiaron Deleuze y Guattari, de manera axiomática ${ }^{17}$, es decir, sin tener que explicar o justificar lo que hace, actuando de forma esquizofrénica a través de desterritorializaciones y reterritorializaciones, descodificando y recodificando de nuevo, pero manteniendo siempre en funcionamiento una máquina jerárquica que controla, aprecia, deprecia, vende y compra la vida sin importarle si es o no humana ${ }^{18}$. Por ello mismo, la resistencia teórica a estos flujos de capital no puede quedarse en una defensa acrítica de la tradición humanista, ya que, en cuanto la dominación es posthumana, las líneas de fuga también deberían serlo. Lo contrario sería simplemente un error conceptual y político que nos dejaría atados a ese viejo excepcionalismo humano que no está a la altura de los tiempos presentes.

Al principio, nos recuerda Braidotti, sólo estaba Él: "el ideal clásico del Hombre, identificado por Protágoras como 'la medida de todas las cosas', luego elevado

\footnotetext{
${ }^{14}$ Ver, especialmente, Foucault, M., Defender la sociedad. Curso en el Collège de France (1975-1976), Buenos Aires, Fondo de Cultura Económica, 2000.

15 Para una crítica de la retórica del capital humano, ver Santamaría, A., En los límites de lo posible. Política, cultura y capitalismo afectivo, Madrid, Akal, 2018, 63-84.

16 Braidotti, R., Por una política afirmativa. Itinerarios éticos, trad. de J.C. Gentile, Barcelona, Gedisa, 2018, p. 137.

${ }_{17}$ Ver, por ejemplo, Deleuze, G., y Guattari, F., El Anti Edipo. Capitalismo y esquizofrenia, Barcelona, Paidós, 1985 , pp. $145-146$.

18 Ver Braidotti, R., Por una política afirmativa. Itinerarios éticos, op. cit., pp. 123-124.
} 
por el Renacimiento italiano a modelo universal" ${ }^{19}$. No olvidemos que este Renacimiento coincide estrictamente en términos cronológicos con el inicio de la conquista europea de los Otros, tanto de sus territorios como de sus culturas, que fueron devoradas y luego vomitadas ya transformadas en cadenas de valor de un mercado universal. El humanismo ha funcionado fundamentalmente como una fe en la potenciación de nuestras capacidades biológicas, racionales y morales, a la luz de una concepción del progreso orientado teleológicamente. Walter Benjamin ya nos advirtió, en las horas más oscuras del siglo XX, de que la cara oculta de esa visión del progreso escondía un huracán de catástrofes (Tesis IX) y de que no hay documento de cultura que no sea a la vez un documento de barbarie (Tesis VII) ${ }^{20}$. Esta fe progresista, sin embargo, continúa vigente, según Braidotti, en los cantos a la inmaterialidad de la conciencia que entonan los gurús tecnológicos, así como en las fantasías de fuga transhumanista típicos de la euforia neoliberal, que recaen una y otra vez en ese realismo capitalista según el cual es más fácil imaginar el fin del mundo que el fin del capitalismo ${ }^{21}$. La cuestión es que el humanismo ha sido, más que una orientación individual, todo "un modelo de civilización, que ha plasmado la idea de Europa como coincidente con los poderes universalizantes de la razón autorreflexiva" ${ }^{22}$. Braidotti apunta a Hegel como el encargado de canonizar esta hegemonía intelectual de Europa en su filosofía de la historia, en "una perspectiva autocomplaciente" para la que Europa no es otra ubicación geopolítica más, sino una especie de atributo del pensamiento que presta sus beatíficas cualidades civilizatorias a cualquier objeto que se ponga en el camino del Espíritu ${ }^{23}$.

El mismo Hegel también señala que Spinoza, "como judío que es", elabora una concepción monista de la materia, que rechaza el dualismo alma-cuerpo o cultura-naturaleza, y que esto debe entenderse como un "eco del pensamiento oriental" y, por tanto, no propiamente europeo ${ }^{24}$. Este racismo implícito explica la poca afinidad de Braidotti — exponente contemporáneo del nomadismo filosófico iniciado por Deleuze y Guattari ${ }^{25}$ - con el sistema hegeliano, el cual entiende el progreso racional como un violento choque dialéctico entre conciencias, que desembocaría inevitablemente en un eurocentrismo que desprecia otras vías de acceso al cono-

\footnotetext{
${ }_{19}$ Braidotti, R., Lo posthumano, op.cit., p. 25.

${ }^{20}$ Benjamin, W., "Sobre el concepto de historia”, en Obras, libro I/ vol. 2, Madrid, Abada, 2008, pp. 309-310.

21 Ver Fisher, M., Realismo capitalista. ¿No hay alternativa?, trad. de Claudio Iglesias, Buenos Aires, Caja Negra, 2018, pp. 21-34.

22 Braidotti, R., Lo posthumano, op. cit., p. 26.

${ }^{23}$ Ver Ibid., pp. 26-27.

${ }^{24}$ Ver Hegel, G.W.F., Lecciones sobre la historia de la filosofía, vol. III, trad. de Wenceslao Roces, México, Fondo de Cultura Económica, 1977, p. 280.

25 Sobre la interpretación que hace la pensadora italiana del nomadismo filosófico, ver su obra Braidotti, R., Nomadic Subjects, New York, Columbia University Press, 2011.
} 
cimiento. En palabras del filósofo hindú Partha Chatterjee: "el provincialismo de la experiencia europea será tomado como la historia universal del progreso" ${ }^{26}$. La verdad incómoda que oculta la teatralización intelectual del humanismo occidental es que éste ha acabado por ser un imperialismo capaz de justificar genocidios. Braidotti se muestra clara y vehemente en su denuncia de la violencia humanista:

Este paradigma eurocéntrico implica la dialéctica entre el ego y el otro, además de la lógica binaria de la identidad y la alteridad, en calidad de motores de la lógica cultural del humanismo universal. Es central, por esta actitud universalista y por su lógica binaria, la noción de diferencia, entendida en sentido peyorativo. El sujeto equivale a la conciencia, a la racionalidad universal y al comportamiento ético autodisciplinante, mientras que la alteridad es concebida como su contraparte especulativa y especular. No obstante, cuando la palabra diferencia significa inferioridad, éste asume connotaciones esencialistas y letales desde el punto de vista de las personas marcadas como "otras". Estos son los otros sensualizados, racializados y naturalizados, reducidos al estado no humano de cuerpos de usar y tirar. Nosotros somos todos humanos, sólo que algunos de nosotros son más mortales que $\operatorname{otros}^{27}$.

Ahora que ya sabemos, gracias a la labor de desmontaje de las teorías feministas y decoloniales, que este modelo de Hombre Universal, basado en el varón, blanco, cristiano, hablante de una lengua europea, urbanita y heterosexual, es indefendible por su escasa representatividad en términos de la población mundial ${ }^{28}$, debemos dar un paso más allá para salir de este opresivo laberinto conceptual que funciona como productor incansable de pasiones tristes y comportamientos depredadores. $\mathrm{Y}$ dado que el modo de producción global ha devenido post-antropocéntrico, pues está actualmente centrado en la producción de inteligencias artificiales y en la manipulación genética de especies no humanas, Braidotti, como orgullosa filósofa posthumana, nos anima a vivir sin miedo el "éxodo antropológico" 29.

Esta línea de fuga desplaza la centralidad del anthropos para acercarnos a un igualitarismo zoe-centrado ${ }^{30}$, definiendo zoe como la potencia generadora de la vida, eliminando, de este modo, el binarismo que separa y jerarquiza el bios —esto es, la vida humana - de la vida que anima al resto de la materia orgánica. Nuestra autora se reclama discípula de maestros antihumanistas como Foucault, Deleuze e Irigaray, de los cuales recoge ideas y las problematiza para pensar los devenires de nuestro presente. Sin embargo, en sus últimos trabajos va a preferir remontarse más

\footnotetext{
${ }^{26}$ Chatterjee, P., La nación en tiempo heterogéneo y otros estudios subalternos, trad. de R. Vera y R. Hernández Asensio, Buenos Aires, Siglo XXI, 2008, p. 176.

27 Braidotti, R., Lo posthumano, op. cit., p. 27.

${ }^{28}$ Ver Ibid., p. 82.

29 Ídem.

${ }^{30}$ Ver Ibid., pp. 77 y 112.
} 
atrás para encontrar una plataforma reflexiva sobre la que desplegar un materialismo radical y vitalista, para desechar el excepcionalismo humano como categoría trascendental y para introducirse en las potencialidades de la inmanencia. Esa plataforma es una ética que, al mismo tiempo, también es una ontología política, y la encuentra en esa "anomalía salvaje" del pensamiento moderno que es la obra de Baruch Spinoza ${ }^{31}$.

\section{Más allá de la vulnerabilidadः hacia una ética posthumana de la afirmación}

En su техто Nueva ilustración radical, la filósofa española Marina Garcés trabaja con varias hipótesis de trabajo para abordar el tema de la crisis de las humanidades ante dos tipos de respuestas, una defensiva-nostálgica y otra tecnoutópica, que encuentra insatisfactorias porque nos alejan de los retos del presente al proyectarnos al pasado o al futuro según el caso. De esta forma, señala que "el hecho epistemológico más relevante de nuestro presente es el redescubrimiento de la continuidad naturaleza-cultura" y se pregunta: “¿somos capaces de proponer y articular otros sentidos de este reencuentro entre naturaleza y cultura que no se sometan a las pautas de su explotación por parte del capitalismo actual". A su entender, esta cuestión sería "el punto de partida desde donde las humanidades pueden empezar a redefinir, hoy, los sentidos de la emancipación" 32 .

Para Braidotti, es justamente este continuum naturaleza-cultura lo que supone el punto de partida de una teoría posthumana ${ }^{33}$, de un pensamiento que se haga cargo de la realidad del capitalismo bio-cognitivo, el mismo que ya hace negocios desde hace mucho sin hacer distinciones entre lo dado y lo construido. Esta continuidad revela, además, los límites de la perspectiva socioconstructivista que, si bien sirve para evidenciar cómo la desigualdad y las injusticias de origen social pasan a ser naturalizadas, sigue manteniendo una lógica binaria que no da cuenta del hecho de que naturaleza y cultura forman parte del mismo mundo de la vida y se afectan recíprocamente de manera constante e ininterrumpida. En lenguaje spinoziano, sus

\footnotetext{
31 En palabras de Antonio Negri: "La anomalía del pensamiento de Spinoza respecto a su tiempo se hace, por tanto, anomalía salvaje. Salvaje porque está articulada en la densidad y multiplicidad de afirmaciones que surgen de la extensa afabilidad de lo infinito. Existe en Spinoza el placer del ser infinito; que es placer del mundo...El término "anomalía salvaje" no reenvía pues solamente a la colocación histórica del pensamiento de Spinoza en su tiempo y en el desarrollo de la filosofía occidental, no es sólo una cualificación de la riqueza de su pensamiento y de su apertura al porvenir: es además un momento fundamental y un modo propio de la expresión del ser". Negri, A., La anomalía salvaje. Ensayo sobre poder y potencia en Baruch Spinoza, trad. de G. de Pablo, Barcelona, Anthropos, 1993, pp. 364-365.

32 Garcés, M., Nueva ilustración radical, Barcelona, Anagrama, 2017, pp. 69-70.

33 Ver Braidotti, R., Lo posthumano, op. cit., p. 12.
} 
expresiones singulares serían, pues, modos finitos de la misma sustancia infinita. El constructivismo está dejando de ser útil y apropiado para nuestros tiempos desde el momento en que "los confines entre las categorías de lo natural y lo cultural han sido desplazados y, en gran medida, se han esfumado por los desarrollos científicos y tecnológicos" ${ }^{34}$. De ahí que sea necesario dar paso a una teoría no dualista que se apoye en la tradición filosófica monista, la cual sostiene una concepción de una materia viva capaz de autoorganización y, al mismo tiempo, no naturalista. ¿Pero cómo, por qué caminos, podemos alcanzar una teoría social y política que explique y transforme esta nueva condición posthumana? Braidotti suele escribir en primera persona, desde una perspectiva ubicada, sin caer en impostadas voces neutrales. Así, nuestra autora declara:

Yo interpreto el monismo spinozista, y las formas inmanentes de crítica radical que se basan en él, como un movimiento democrático que promueve una especie de pacifismo ontológico. La igualdad de las especies en el mundo postantropocéntrico nos insta a dudar de la violencia y el pensamiento jerárquico que derivan de la arrogancia humana y la hipótesis del excepcionalismo trascendental humano. Una aproximación spinozista, reinterpretada gracias a Deleuze y Guattari, nos permite superar los obstáculos del pensamiento binario y centrar la problemática medio ambiental en toda su complejidad ${ }^{35}$.

Con esta declaración de intenciones, Braidotti pone sus cartas boca arriba: su recorrido teórico consiste en el retorno a Spinoza iniciado por Deleuze, es decir, en volver a situar en primer plano al deseo como la esencia misma del ser humano ${ }^{36} \mathrm{y}$, por extensión, al conatus de todos los cuerpos por perseverar en su ser. Rechaza de esta manera una concepción del deseo como falta o carencia, mantenida tanto por la tradición hegeliana como por el psicoanálisis de impronta lacaniana que, en su opinión, adolecen de una consideración productiva de la negatividad ${ }^{37}$, algo que vuelve a situar estas aproximaciones en el ámbito de un pensamiento binario que debería ser dejado atrás. El monismo que interesa a Braidotti es el de la interpretación deleuziana de esa ética ontológica tejida por Spinoza, que gira en torno a "una única sustancia absolutamente infinita...que posee todos los atributos y cuyos productos son los modos, las maneras de ser" ${ }^{38}$. Esta concepción tiene una consecuencia anárquica que debe ser tomada en consideración, a saber, que "no hay ninguna jerarquía entre los atributos, uno no vale más que otro [...] si el pensamiento es un

\footnotetext{
${ }^{34}$ Ibid., p. 13.

35 Ibid., p. 104.

36 Ver Spinoza, B., Ética, op. cit., III, Definiciones de los afectos, p. 284.

37 Ver Braidotti, R., Metamorfosis. Hacia una teoría materialista del devenir, trad. de A. Varela Mateos, Madrid, Akal, 2005, pp. 98-99.

38 Deleuze, G., En medio de Spinoza, Buenos Aires, Editorial Cactus, 2011, p. 27.
} 
atributo de Dios y lo extenso [o el cuerpo] es un atributo de Dios o de la sustancia, no habrá entre ellos ninguna jerarquía" 39 .

Esto lo sirve a Braidotti para posicionarse dentro de los debates del feminismo contemporáneo donde ella opta por un "regreso a la carne" ${ }^{40}$, una posición crítica con la deriva semiológica o lingüística que no da cuenta de que el cuerpo ya está desde siempre sexuado en un eje múltiple e inabarcable, y que esas diferencias marcan una apertura llena de posibilidades emancipatorias. Estas singularidades no logran ser comprendidas por ninguna política identitaria del reconocimiento, como las que proliferan a partir de la división constructivista sexo/género. "[Judith] Butler opta por el giro lingüístico; yo tomo la senda nómada de la carne" ${ }^{41}$, enfatiza Braidotti. Esta querella teórica entre dos formas diferentes de entender y estudiar la diferencia sexual se ha prolongado también hacia el tema que ha ido adquiriendo cada vez mayor relevancia en la obra de Judith Butler: nos referimos al énfasis en la vulnerabilidad humana, en su precariedad y fragilidad, en el hecho de que nuestros cuerpos pueden herir y ser heridos ${ }^{42}$. Para Braidotti, sin embargo, representa un error conceptual dar prioridad ética o política a la vulnerabilidad humana, ya que este no es un problema que deba o pueda ser resuelto, como pretenden los delirios tecnófilos que buscan el mejoramiento humano. Ni siquiera es un rasgo definitorio de los seres humanos, sino un rasgo común que comparten todas las entidades vivas $^{43}$. Por ejemplo, los efectos potencialmente fatales e irreversibles del cambio climático están impulsando un tipo de interconexión negativa en torno al "vínculo panhumano de la vulnerabilidad", articulándose una solidaridad a partir de la posible extinción de nuestra especie ${ }^{44}$. De las vinculaciones en torno a las pasiones tristes, como el miedo a la desaparición de la humanidad, Braidotti, sin embargo, no espera nada que vaya más allá de nuevas formas de moral o de un falaz humanismo compensatorio que se extienda al resto de las especies. Lo que supondría, a su vez, otra oportunidad perdida para la creación colectiva de una ética afirmativa surgida de las potencialidades, casi siempre despreciadas, de nuestros cuerpos afectados por las infinitas formas mutables de la materia viva.

Nuestra autora, por su parte, siguiendo a su maestro Gilles Deleuze, se toma en serio dos advertencias que Spinoza expone en su Ética. La primera es que "nadie,

${ }^{39}$ Ibid., pp. 27-28.

${ }^{40}$ Braidotti, R., Metamorfosis. Hacia una teoría materialista del devenir, op. cit., p. 67.

${ }^{41}$ Ídem.

${ }^{42}$ Entre estos trabajos de Butler, destacamos: Precarious Life. The Powers of Mourning and Violence, New York, Verso, 2004; y Frames of War. When is Life Grievable?, New York, Verso, 2009.

${ }^{43}$ Ver Braidotti, R., "El feminismo tiene más recursos que la mayoría de culturas políticas para tratar los derechos de los animales", entrevista realizada por Catia Faria en Pikara Magazine, 27/02/2019, disponible en: https:// www.pikaramagazine.com/2019/02/rosi-braidotti/. (consultado: 23/01/2020).

${ }_{44}$ Ver Braidotti, R., Lo posthumano, op. cit., p. 80. 
hasta ahora, ha determinado lo que puede un cuerpo" ${ }^{45}$, pero sabemos por experiencia que "el cuerpo, en virtud de las solas leyes de su naturaleza, puede hacer muchas cosas que resultan asombrosas a su propia alma" ${ }^{46}$. La segunda, como consecuencia de la anterior, es que "cuando los hombres dicen que tal o cual acción del cuerpo proviene del alma, por tener ésta imperio sobre el cuerpo, no saben lo que dicen, y no hacen sino confesar, con palabras especiosas su ignorancia" ${ }^{47}$. Así, la idea de libertad que solemos mantener se reduce al desconocimiento de la causa de nuestras acciones. Despiadadamente, Spinoza ridiculiza a quienes piensan que las acciones humanas dependen de la voluntad y de cómo esta moviliza el cuerpo, diciendo de ellos que "suelen mover a risa o asco" ${ }^{48}$.

De ahí que Braidotti defienda una política de la afirmación que parta del presupuesto del desgobierno de nuestros mundos internos, es decir, de la comprensión y de la aceptación de la finitud de la voluntad humana. Es decir, afirmarnos a partir de nuestros límites, aceptando lo que es posible y realizable en los marcos contingentes donde pasamos nuestra vida. Y aceptando, además, que no estamos solos, que nunca y de ninguna manera estamos solos, sino siempre insertos de manera inmanente en un haz de flujos y relaciones que escapan al control paranoico de nuestra conciencia y nos devuelven a nuestra relación de interdependencia recíproca con todos los que nos rodean, sean éstos humanos o no. Por esta razón, una ética afirmativa sólo puede pensarse en común, lo que la convierte en el acto en una política que piensa globalmente y actúa localmente. Y que, de manera irrenunciable, debe basarse en la transformación de la impotencia del aislamiento en una potencia de acción colectiva, convirtiendo los afectos tristes en pasiones alegres ${ }^{49}$.

$\mathrm{Al}$ fin y al cabo, Spinoza nos revela algo muy sencillo: la tristeza no nos vuelve más inteligentes o capaces. Al contrario, como apunta Deleuze glosando la ética spinoziana: "los afectos tristes son todos aquéllos que disminuyen nuestra potencia de obrar. Y los poderes establecidos necesitan de ellos para convertirnos en esclavos...los poderes tienen más necesidad de angustiarnos que de reprimirnos" ${ }^{50}$. Braidotti deja claro, no obstante, que no se trata de optimismo, que es otra ideología del capitalismo avanzado, sino de la defensa de la alegría como un afecto subversivo que pone en jaque el conservadurismo dicotómico de los valores morales ${ }^{51}$. Ya no

45 Spinoza, B., Etica, op. cit., III, prop. 2, esc., p. 213.

${ }^{46}$ Ibid.,II, prop. 35, esc., p. 214.

47 Ídem.

${ }^{48}$ Spinoza, B., Ética, op. cit., II, prop. 35, esc., p. 172.

${ }^{49}$ Sobre el uso situado de esta ética afirmativa, que tiene su raíz en Spinoza, en los procesos de subjetivación posthumanos, ver Braidotti, R., El conocimiento posthumano, trad. de Júlia Ibarz, Barcelona, Gedisa, 2020, cap. 2.

${ }^{50}$ Deleuze, G., y Parnet, C., Diálogos, trad. de José Vázquez, Valencia, Pre-textos, p. 71.

${ }^{51}$ Ver Braidotti, R., "El feminismo tiene más recursos que la mayoría de culturas políticas para tratar los derechos de los animales", op. cit. 
se trata de la lucha dialéctica entre el Bien y el Mal, es decir, del campo de la moral y el sistema del juicio, sino de una ética o etología de fuerzas acerca de lo bueno y lo malo, lo alegre y lo triste, lo que nos potencia y lo que nos despotencia, pero no desde un protocolo o reglamente establecido y con aspiraciones universalistas, sino desde una perspectiva contingente y situada como la vida misma, capaz de potenciar el deseo de cuidarnos y afectarnos de alegría.

Una ética afirmativa sólo puede basarse en deseos y en la modulación de las intensidades de esos mismos deseos. Puesto que Spinoza nos hizo entender que "nosotros no intentamos, queremos, apetecemos ni deseamos algo porque lo juzguemos bueno, sino que, al contrario, juzgamos que algo es bueno porque lo intentamos, queremos, apetecemos y deseamos" ${ }^{52}$, pretender invertir esta relación sólo conduce al resentimiento y al odio a la complejidad de lo que supone estar vivo. La afirmación por la que apuesta Braidotti se asienta en una comprensión de que la vida que habito no es mía, no me pertenece, sino que es una relación de potencias impersonales y generadoras de devenir sin una finalidad preestablecida ${ }^{53}$. Una comprensión similar es la que hace decir a Hasana Sharp, otra feminista spinozista, que lo impersonal también es politico ${ }^{54}$.

Ahora bien, pensar con el cuerpo sin emprender el vuelo hacia una conciencia trascendental quiere decir confrontarse con vínculos y límites que pueden hacernos sufrir. Aunque Braidotti considera los estados melancólicos y la retórica de la lamentación parte constitutiva de la lógica actual del capital, eso no implica que su ética afirmativa desprecie el dolor, la vulnerabilidad o nuestra condición precaria $^{55}$. De este modo, "la ética nómada no quiere negar el dolor; más bien aspira a superar la resignación y la pasividad que siguen a las heridas, las pérdidas y las expropiaciones" ${ }^{56}$. También son dolorosos los procesos de desfamiliarización con nuestros hábitos y ortodoxias más queridas que conlleva esta ética transformadora. El nomadismo filosófico aspira, pues, a un devenir ético como proceso de autoprotección, en contraste con las reglas implacables de las morales universalistas. Desde el momento en que el punto de partida de Spinoza nunca es el individuo aislado, sino el cuerpo interdependiente, los límites de éste son asimismo los límites de nuestra potencia de devenir. Una ética debe, por tanto, buscar unos "umbrales de sostenibilidad" diferenciados para cada vida concreta, para cada cuerpo arraigado, encarnado y limitado, aun cuando los límites no sean entendidos como barreras,

\footnotetext{
52 Spinoza, B., Ética, op. cit., III, prop. 9, esc., p. 223.

53 Ver Braidotti, R., Por una politica afirmativa. Itinerarios éticos, op. cit., p. 133.

${ }^{54}$ Ver Sharp, H., Spinoza and The Politics of Renaturalization, Chicago, The University of Chicago Press, 2011, pp. $155-184$.

55 Ver Braidotti, R., Por una politica afirmativa. Itinerarios éticos, op. cit., p 169.

56 Ibid., p. 174.
} 
sino como punto de paso en nuestro devenir ético ${ }^{57}$. En este sentido, escribe Braidotti, "la expresión 'no puedo más' es una declaración ética, no la afirmación de una derrota" 58 .

\section{No-conclusión}

Hay un punto delicado donde la lectura de Braidotti puede hacer ruido a otros intérpretes de Spinoza, ya que pareciera que a nuestra autora le cuesta separarse de la confianza humanista en un futuro mejor. Así, ella sigue aferrada a la idea de constituir lo que denomina "horizontes sociales de esperanza" 59 como parte del compromiso de esta ética y política afirmativa. A raíz de lo que dejó escrito el pensador sefardí no podemos dar una interpretación sencilla a esta propuesta de Braidotti. En su Ética concluía que "no hay esperanza sin miedo, ni miedo sin esperanza", siendo la interrelación entre estos dos afectos el origen de las supersticiones que acosan a los seres humanos por doquier ${ }^{60}$. Al estar la esperanza ligada al miedo y las religiones, también podría ser concebida como uno de los instrumentos que utilizan los dominadores para que los humanos luchen por su servidumbre como si se tratara de su salvación ${ }^{61}$. En su propuesta ética, la esperanza es un afecto triste que no puede ser bueno de por sí porque revela una falta de conocimiento y una impotencia del alma ${ }^{62}$. Deleuze nos advierte, además, haciendo precisamente referencia al afecto de la esperanza, que "Spinoza no es de lo que piensan que una pasión triste pueda ser buena bajo algún aspecto" ${ }^{63}$. Una política spinozista, por tanto, buscaría sustraerse de estas creencias supersticiosas, aun sabiendo la dificultad que entraña esta empresa, que en sí misma consiste en un proceso de liberación tanto del miedo como de la esperanza, porque "un hombre libre en nada piensa menos que en la muerte, y su sabiduría no es una meditación de la muerte, sino de la vida" ${ }^{64}$.

Ahora bien, asimismo leemos en su Tratado politico que "una multitud libre se guía más por la esperanza que por el miedo, mientras que la sojuzgada se guía más por el miedo que por la esperanza. Aquélla, en efecto, procura cultivar la vida,

\footnotetext{
57 Sobre la concepción de "sostenibilidad" en la propuesta ética de Braidotti, ver ibid., pp. 156-169.

58 Ibid., p. 168.

59 Ibid., pp. 141-142.

${ }_{60}$ Ver Spinoza, B., Ética, op. cit., III, prop. 50, esc., p. 267.

${ }^{61}$ Ver Spinoza, B., Tratado teológico-político, op. cit., Prefacio, p. 64.

${ }^{62}$ Ver Spinoza, B., Etica, op. cit., IV, prop. 47. Así, en el escolio de esta proposición, Spinoza escribe: "cuanto más nos esforzamos por vivir según la guía de la razón, tanto más nos esforzamos en no depender de la esperanza”, p. 368.

63 Deleuze, G., Spinoza: filosofía práctica, op. cit., p. 37.

${ }^{64}$ Spinoza, B., Etica, op. cit., IV, prop. 67, p. 389.
} 
ésta, en cambio, procura evitar simplemente la muerte" "ㄷ. ¿Se contradice Spinoza? Probablemente. Pero si creemos a Hannah Arendt, "estas contradicciones tan fundamentales y flagrantes pocas veces se presentan en escritores de segunda línea, en quienes pueden descontarse. En los grandes autores nos llevan hasta el centro mismo de sus obras y son la clave más importante para llegar a la verdadera comprensión de sus problemas y sus nuevos criterios" ${ }^{66}$. No obstante, este camino intrincado hacia el centro de la obra de Spinoza debo dejarlo para otra ocasión.

65 Spinoza, B., Tratado político, op. cit., cap. V, $\$ 16$, p. 120.

${ }^{66}$ Arendt, H., "La tradición y la época moderna", en Entre el pasado y el futuro. Ocho ejercicios de reflexión politica (1968), trad. de Ana Poljak, Barcelona, Península, 1996, p. 31. 


\section{REFERENCIAS BIBLIOGRÁFICAS}

Arendt, H., "La tradición y la época moderna", en Entre el pasado y el futuro. Ocho ejercicios de reflexión política (1968), trad. de Ana Poljak, Barcelona, Península, 1996.

Balza, I., "Los feminismos de Spinoza: corporalidad y renaturalización", en Daimon. Revista Internacional de Filosofía, ${ }^{\circ} 63$ (2014), pp. 13-26. https://doi. org/10.6018/daimon/199491

Benjamin, W., "Sobre el concepto de historia”, en Obras, libro I/ vol. 2, Madrid, Abada, 2008, pp. 303-318.

Braidotti, R., "El feminismo tiene más recursos que la mayoría de culturas políticas para tratar los derechos de los animales", entrevista realizada por Catia Faria en Pikara Magazine, 27/02/2019, disponible en: https://www.pikaramagazine. com/2019/02/rosi-braidotti/. (consultado: 23/01/2020).

Braidotti, R., El conocimiento posthumano, trad. de Júlia Ibarz, Barcelona, Gedisa, 2020.

Braidotti, R., Por una politica afirmativa. Itinerarios éticos, trad. de J.C. Gentile, Barcelona, Gedisa, 2018.

Braidotti, R., Lo posthumano, trad. de J. C. Gentile, Barcelona, Gedisa, 2015.

Braidotti, R., Nomadic Subjects, New York, Columbia University Press, 2011.

Braidotti, R., Metamorfosis. Hacia una teoría materialista del devenir, trad. de A. Varela Mateos, Madrid, Akal, 2005.

Butler, J., Precarious Life. The Powers of Mourning and Violence, New York, Verso, 2004.

Butler, J., Frames of War. When is Life Grievable?, New York, Verso, 2009.

Casassas, D., Libertad incondicional: la renta básica en la revolución democrática, Barcelona, Paidós, 2018.

Chatterjee, P., La nación en tiempo heterogéneo y otros estudios subalternos, trad. de R. Vera y R. Hernández Asensio, Buenos Aires, Siglo XXI, 2008.

Deleuze, G., En medio de Spinoza, Buenos Aires, Editorial Cactus, 2011.

Deleuze, G., Spinoza: filosofía práctica, trad. de A. Escohotado, Buenos Aires, Tusquets, 2004. 
Deleuze, G., y Guattari, F., El Anti Edipo. Capitalismo y esquizofrenia, Barcelona, Paidós, 1985.

Fisher, M., Realismo capitalista. ¿No hay alternativa?, trad. de Claudio Iglesias, Buenos Aires, Caja Negra, 2018.

Foucault, M., Defender la sociedad. Curso en el Collège de France (1975-1976), Buenos Aires, Fondo de Cultura Económica, 2000.

Garcés, M., Nueva ilustración radical, Barcelona, Anagrama, 2017.

Hegel, G.W.F., Lecciones sobre la historia de la filosofía, vol. III, trad. de Wenceslao Roces, México, Fondo de Cultura Económica, 1977.

Negri, A., La anomalía salvaje. Ensayo sobre poder y potencia en Baruch Spinoza, trad. de G. de Pablo, Barcelona, Anthropos, 1993.

Sharp, H., Spinoza and the Politics of Renaturalization, Chicago: The University of Chicago Press, 2011.

Sharp, H., "Eve's Perfection: Spinoza on Sexual (In)Equality”, en Journal of the History of Philosophy, vol. 50, n 4 (2012), pp. 564-565. https://doi.org/10.1353/ hph.2012.0068

Sharp, H., “¿Por qué Spinoza y el feminismo?”, Reflexiones marginales, $\mathrm{n}^{\circ} 51$ (2019), consultado en https://2018.reflexionesmarginales.com/por-que-spinoza-y-el-feminismo/ (consultado: 21/01/2020).

Raventós, D., y Casassas, D., "La renta básica y el poder de negociación de 'los que viven con permiso de otros", en Revista Internacional de Sociología (RIS), $\mathrm{n}^{\circ}$ 34 (2003), pp. 187-201. https://doi.org/10.3989/ris.2003.i34.291

Santamaría, A., En los límites de lo posible. Política, cultura y capitalismo afectivo, Madrid, Akal, 2018.

Segato, R.L, La guerra contra las mujeres, Madrid, Traficantes de sueños, 2016.

Spinoza, B., Tratado político, trad. de A. Domínguez, Madrid, Alianza, 1986.

Spinoza, B., Tratado teológico-político, trad. de A. Domínguez, Barcelona, Altaya, 1997.

Spinoza, B., Ética, trad. de V. Peña, Madrid, Alianza, 2011.

DOI: https://doi.org/10.15366/bp2021.27.003

Bajo Palabra. II Época. No 27. Pgs: 63-80 